\title{
Importance of sex differences in impulse control and addictions
}

\author{
Marci R. Mitchell ${ }^{1 *}$ and Marc N. Potenza ${ }^{1,2,3,4}$ \\ ${ }^{1}$ Department of Psychiatry, Yale University School of Medicine, New Haven, CT, USA \\ ${ }^{2}$ Department of Neurobiology, Yale University School of Medicine, New Haven, CT, USA \\ ${ }^{3}$ Child Study Center, Yale University School of Medicine, New Haven, CT, USA \\ ${ }^{4}$ CASAColumbia, Yale University, New Haven, CT, USA \\ *Correspondence: marci.mitchell@yale.edu \\ Edited by: \\ Liana Fattore, National Research Council, Italy \\ Reviewed by: \\ Jana Kucerova, Masaryk University, Czech Republic \\ Carmela M. Reichel, Medical University of South Carolina, USA
}

Keywords: sex differences, hormone effects, gender, impulsivity, addictions

Historically, sex- or gender-related differences in addictions have been understudied. When neglected, both sexes may not receive the full benefit of medical research. Although hormone fluctuations in women are rarely investigated with respect to treatments, levels of estrogen and progesterone may have large impacts on the efficacies of behavioral or pharmaceutical interventions (1-7). The National Institutes of Health (NIH) have been advocating for investigating gender-related differences and hormonal influences (8), including with respect to impulse control and its contributions to addictions. Despite the importance of studying sex differences, the standard integration of sex-difference considerations, including in preclinical research using cell lines and animals, has yet to occur.

Sex differences are present in personality traits and behaviors, such as impulsivity, that have been associated with addictions (both substance and non-substance). Impulsivity has been defined as a tendency to act with little foresight or little consideration of future consequences $(9,10)$. Impulsivity is a complex construct that may be separated into specific factors; two main domains that can be measured in the laboratory include impulsive action and impulsive choice (11). Both impulsive action and choice have been associated with drug use, in both a predictive fashion and as a result of drug use $(12,13)$. Work investigating sex differences in impulsive action in both animals and humans has shown mixed results (14). The mixed findings may in part relate to sex hormones, with females displaying fluctuating levels of impulsivity dependent on cycle phase and estrogen levels (14).

Impulsive choice has been measured in the laboratory using delay-discounting tasks $(13,15-17)$. While multiple studies suggest that men may be more impulsive than women, careful investigation of specific facets suggest otherwise. Women may display greater discounting rates than men (i.e., greater choice impulsivity); however, reward type is relevant as men have been found to discount real money more rapidly than women, with women discounting hypothetical rewards more rapidly than men (18). Among adolescents, female smokers appear more impulsive than male smokers, but male control subjects appear more impulsive than female control subjects (19). Consistent with findings from Kirby and Marakovic (18); Heyman and Gibb (20) found that female smokers also tend to discount the value of hypothetical rewards more rapidly than do males.

Among heavy drinkers, women exhibit poorer inhibitory control than men (21, 22). A study investigating the neural correlates of impulsivity in non-abusing individuals who were family-history positive for alcohol abuse found that those who are family-history positive show greater recruitment of brain regions involved in addiction, inhibitory control, and executive function compared to those without family histories of alcoholism; however, this effect was driven by males (23). Had gender differences not been built into the experimental design, such a finding would not have been identified. Although there exist strong associations between drug use and impulsivity in both humans and animals, with impulsivity increasing the propensity for drug use and vice-versa $(12,13,24$, 25), few studies have investigated sex differences, particularly in preclinical work. The possible roles for cycle phase or circulating hormones in delay-discounting-task performance warrant further study.

Impulsivity and behavioral performance in impulsivity tasks does not always differ between men and women; however, that does not mean that both sexes are achieving similar performance in the same way. Even when men and women perform comparably in inhibitory tasks, different neurobiologies may underlie the behaviors. For example, in a recent study of genderrelated differences in neural factors associated with performance of the stop-signal task, men tended to show more activation in the lentiform nucleus, parahippocampal gyrus, posterior and anterior cingulate cortices, middle and medial frontal cortices, and thalamus, compared to women, despite similar performance on the task (26). In general, men and women display different brain connectivity patterns, both in adolescence and adulthood. One study found that men show greater within-hemispheric connectivity and women show greater acrosshemispheric activity, suggesting that male brains may be better suited to facilitate connectivity between perception and coordinated action, whereas female brains may be better suited to facilitate communication between analytical and intuitive processes (27). As neurobiological differences in males and females start in early stages of development $(28,29)$, it may be difficult to 
determine which differences are the result of genetics, which are influenced by cycling hormones and which may arise through interactions and other processes. Some differences may arise from how similarly conserved genes across the sexes are translated and expressed differently depending on $\operatorname{sex}(30)$.

Although men and women may use the same drugs and display the same behavioral addictions, frequencies may vary by drugs and behaviors (31). Furthermore, addictions may present differently, have different courses and patterns of comorbidity, be driven by different motivations, and have different factors leading to relapse $(14,32,33)$. Males typically have higher rates of drug use and are more likely to develop dependence or abuse; however, women may have transition from initial use to dependence more quickly. Preclinical and clinical data suggest an enhanced vulnerability to drug use with greater acquisition of drug self-administration in females as compared to males $(32,34-40)$.

Given apparent sex differences in susceptibilities to drug use, sex differences in the approach to treating drug use and drug-use disorders are important to consider in order to optimize interventions for each sex. A recent study investigating sex differences in the efficacy of disulfiram in cocaine and alcohol dependence found that women, compared to men, had poorer treatment outcomes on several measures of cocaine use during treatment and at post-treatment follow-up, which was primarily accounted for by disulfiram being less effective in women than men (41). Gonadal hormones may influence relationships with treatment outcomes as estrogen may enhance the rewarding properties of drugs whereas progesterone may be more protective and attenuate drugrewarding effects $(5,7,42)$. Severity of withdrawal symptoms may vary based on menstrual-cycle phase (1-4). Moreover, estrogen interactions with dopamine transmission or the hypothalamic-pituitaryadrenal (HPA) axis may partially underlie facilitative effects (43-45). For example, females may be more affected by stress and report stress as a reason for drug use and relapse; therefore, greater activation of the HPA axis through stress has the potential to interact with circulating estrogen and monoamine neurotransmitters such as dopamine and serotonin (both implicated in rewarding and motivational aspects of drug use and impulse control) $(34,46,47)$.

Women may be more likely to engage in addictive behaviors for negative reinforcement reasons (e.g., escape from stress) whereas men may be more likely to engage in addictive behaviors for positive reinforcement reasons (e.g., seeking a high), and these motivational differences may reflect different biologies and/or result in different clinical presentations. For example, studies link differences in cortico-striato-limbic activations in cocaine dependence to stress cues in women and drug cues in men (48). Additionally, women more frequently than men present with other mental health issues, such as trauma and depression, that cooccur with addictions (33).

Sex differences may extend to nonsubstance or behavioral addictions like gambling disorder. Women with gambling problems often display a "telescoping" effect similar to women with substance addictions, whereby females often initiate recreational behavior at a later age than men but progress more quickly into problematic gambling $(49,50)$. Males tend to develop problems with "face-toface" forms of gambling (e.g., poker or blackjack), whereas females are more likely to develop problems with less personally interactive forms [e.g., bingo, keno, electronic-gambling (slot) machines], with differences appearing to relate to impaired control over gender-related behavioral preferences evident in recreational gamblers $(49,51)$. Taken together, data suggest important gender-related differences exist that warrant consideration in optimizing policy, prevention, and treatment initiatives.

When investigating the relationships between sex, hormones, impulsivity, and addictions, it will be important to consider research designs. Impulsivity is a multifaceted construct and therefore using tasks assessing specific aspects of impulsivity is important $(52,53)$. Additionally, the reinforcer presented may also be an important variable as males and females may have different motivations relating to consumption of specific reinforcers, and women may discount more quickly than men when rewards are hypothetical. In rodents, no differences were found between males and females in premature responding when the reward was food; however, when the reward was cocaine, female rats made significantly more premature responses (54). It is unclear whether the increase in premature responding in female rats for cocaine was related to cycle phase. High estrogen levels may attenuate impulsive action and depleting male rats of testosterone may decrease impulsive action (55), but high estrogen levels have also been associated with increased sensitivity to cocaine (56). Therefore, it is important to determine whether there are fluctuating levels of impulsivity across different cycle phases and how these might relate to addictions. Additionally, understanding and studying genetic differences (and similarities) between men and women that may underlie behavior and neural activity is important. One way to disentangle potential roles of hormones and genetic factors relating to impulsivity and addiction involves manipulating hormone levels by administering or blocking cycling hormones and using hormone replacement therapy, particularly in females who are in menopause. Moreover, in preclinical models, the use of ovariectomized animals and controlled administration or release of various hormones is possible. Preclinical studies may effectively disentangle influences of genotype (XX, XY) from gonadal phenotype (ovaries, testes) with respect to impulsivityrelated and addiction-related behaviors (57). Applying these techniques in longitudinal studies across the life-span in both females and males could provide important insight into developmental sex differences in impulsivity and addiction, and these findings may inform human research and efforts to develop more effective policy, prevention, and treatment interventions.

In summary, data demonstrate the importance of studying sex differences in addictions and impulsivity and their interactions. While research has progressed in these areas, there remains a deficit in understanding sex differences. While NIH has promoted the study of males and females in clinical populations, sex differences are not uniformly and systematically investigated and influences of circulating hormones are not routinely documented. Therefore, it is difficult to determine which differences may link to hormones and which may link to genetic 
differences between the sexes. In preclinical research, sex differences are often neglected, which may limit the translation of preclinical findings into clinical settings. Routine considerations of sex differences in preclinical and clinical research settings will help advance translational efforts and improve prevention, treatment, and policy initiatives.

\section{ACKNOWLEDGMENTS}

Disclosure of the sources of any support for the work, received in the form of grants and/or equipment and drugs. Supported by: R01DA020908 (MP), P20DA027844 (MP), R01DA035058 (MP), P50DA09241 (MP; Carroll, PI), Connecticut Department of Mental Health and Addiction Services, the Connecticut Mental Health Center, the National Center for Responsible Gaming (MP), T32DA007238 (MM; Petrakis, PI), and K12DA031050 (MM; Mazure, PI) from NIDA, NIAAA, Office of Research on Women's Health (ORWH), and NIH Office of the Director (OD). The content of this manuscript was generated by the authors, was not influenced by the funding agencies, and may not reflect the views of the funding agencies. Drs. MM and MP report no conflicts of interest with respect to the contents of this manuscript. Dr. MP has consulted for Lundbeck, Ironwood, Shire, and INSYS pharmaceuticals and RiverMend Health; received research support from Mohegan Sun Casino, Psyadon Pharmaceuticals, and National Center for Responsible Gambling; has participated in surveys, mailings, or telephone consultations related to drug addiction, impulse-control disorders, or other health topics; and has consulted for gambling, legal, and governmental entities on issues related to addictions or impulsecontrol disorders. The funding agencies did not provide input or comment on the content of the manuscript, which reflects the contributions and thoughts of the authors and not necessarily the views of the funding agencies.

\section{REFERENCES}

1. Sofuoglu M, Dudish-Poulsen S, Nelson D, Pentel PR, Hatsukami DK. Sex and menstrual cycle differences in the subjective effects from smoked cocaine in humans. Exp Clin Psychopharmacol (1999) 7:274-83. doi:10.1037/1064-1297.7.3.274

2. Snively TA, Ahijevych KL, Bernhard LA, Wewers ME. Smoking behavior, dysphoric states and the menstrual cycle: results from single smoking sessions and the natural environment. Psychoneuroendocrinology (2000) 25:677-91. doi:10.1016/S03064530(00)00018-4

3. Terner JM, De Wit H. Menstrual cycle phase and responses to drugs of abuse in humans. Drug Alcohol Depend (2006) 84:1-13. doi:10.1016/ j.drugalcdep.2005.12.007

4. Allen AM, Allen SS, Lunos S, Pomerleau CS. Severity of withdrawal symptomatology in follicular versus luteal quitters: the combined effects of menstrual phase and withdrawal on smoking cessation outcome. Addict Behav (2010) 35:549-52. doi:10.1016/j.addbeh.2010.01.003

5. Quinones-Jenab V, Jenab S. Progesterone attenuates cocaine-induced responses. Horm Behav (2010) 58:22-32. doi:10.1016/j.yhbeh.2009.10.002

6. Quinones-Jenab V, Jenab S. Influence of sex differences and gonadal hormones on cocaine addiction. ILAR J (2012) 53:14-22. doi:10.1093/ilar.53.1.14

7. Devito EE, Herman AI, Waters AJ, Valentine GW, Sofuoglu M. Subjective, physiological, and cognitive responses to intravenous nicotine: effects of sex and menstrual cycle phase. Neuropsychopharmacology (2014) 39:1431-40. doi:10.1038/ npp.2013.339

8. Clayton JA, Collins FS. Policy: NIH to balance sex in cell and animal studies. Nature (2014) 509:282-3. doi:10.1038/509282a

9. Hinslie L, Shatzky J. Psychiatric Dictionary. New York, NY: Oxford University Press (1940).

10. Moeller FG, Barratt ES, Dougherty DM, Schmitz JM, Swann AC. Psychiatric aspects of impulsivity. Am J Psychiatry (2001) 158:1783-93. doi:10.1176/ appi.ajp.158.11.1783

11. Mitchell MR, Potenza MN. Addictions and personality traits: impulsivity and related constructs. Curr Behav Neurosci Rep (2014) 1:1-12. doi:10. 1007/s40473-013-0001-y

12. Perry JL, Nelson SE, Carroll ME. Impulsive choice as a predictor of acquisition of IV cocaine selfadministration and reinstatement of cocaineseeking behavior in male and female rats. Exp Clin Psychopharmacol (2008) 16:165-77. doi:10.1037/ 1064-1297.16.2.165

13. Mitchell MR, Weiss VG, Ouimet DJ, Fuchs RA, Morgan D, Setlow B. Intake-dependent effects of cocaine self-administration on impulsive choice in a delay discounting task. Behav Neurosci (2014) 128:419-29. doi:10.1037/a0036742

14. Weafer J, De Wit H. Sex differences in impulsive action and impulsive choice. Addict Behav (2014) 39:1573-9. doi:10.1016/j.addbeh.2013.10.033

15. Evenden JL, Ryan CN. The pharmacology of impulsive behaviour in rats: the effects of drugs on response choice with varying delays of reinforcement. Psychopharmacology (Berl) (1996) 128:161-70. doi:10.1007/s002130050121

16. Adriani W, Laviola G. Elevated levels of impulsivity and reduced place conditioning with damphetamine: two behavioral features of adolescence in mice. Behav Neurosci (2003) 117:695-703. doi:10.1037/0735-7044.117.4.695

17. Steinberg L, Graham S, O'brien L, Woolard J, Cauffman E, Banich M. Age differences in future orientation and delay discounting. Child Dev (2009) 80:28-44. doi:10.1111/j.1467-8624.2008. 01244.x
18. Kirby KN, Marakovic NN. Modeling myopic decisions: evidence for hyperbolic delay-discounting within subjects and amounts. Organ Behav Hum Decis Process (1995) 64:22-30. doi:10.1006/obhd. 1995.1086

19. Fields S, Collins C, Leraas K, Reynolds B. Dimensions of impulsive behavior in adolescent smokers and nonsmokers. Exp Clin Psychopharmacol (2009) 17:302-11. doi:10.1037/a0017185

20. Heyman GM, Gibb SP. Delay discounting in college cigarette chippers. Behav Pharmacol (2006) 17:669-79. doi:10.1097/FBP.0b013e3280116cfe

21. Townshend JM, Duka T. Binge drinking, cognitive performance and mood in a population of young social drinkers. Alcohol Clin Exp Res (2005) 29:317-25. doi:10.1097/01.ALC. 0000156453.05028.F5

22. Nederkoorn C, Baltus M, Guerrieri R, Wiers RW. Heavy drinking is associated with deficient response inhibition in women but not in men. Pharmacol Biochem Behav (2009) 93:331-6. doi: 10.1016/j.pbb.2009.04.015

23. Devito EE, Meda SA, Jiantonio R, Potenza MN, Krystal JH, Pearlson GD. Neural correlates of impulsivity in healthy males and females with family histories of alcoholism. Neuropsychopharmacology (2013) 38:1854-63. doi:10.1038/npp.2013.92

24. Mendez IA, Simon NW, Hart N, Mitchell MR, Nation JR, Wellman PJ, et al. Self-administered cocaine causes long-lasting increases in impulsive choice in a delay discounting task. Behav Neurosci (2010) 124:470-7. doi:10.1037/a0020458

25. Mitchell MR, Weiss VG, Beas BS, Morgan D, Bizon JL, Setlow B. Adolescent risk taking, cocaine selfadministration, and striatal dopamine signaling. Neuropsychopharmacology (2014) 39:955-62. doi: 10.1038/npp.2013.295

26. Li CS, Huang C, Constable RT, Sinha R. Gender differences in the neural correlates of response inhibition during a stop signal task. Neuroimage (2006) 32:1918-29. doi:10.1016/j.neuroimage. 2006.05.017

27. Ingalhalikar M, Smith A, Parker D, Satterthwaite TD, Elliott MA, Ruparel K, et al. Sex differences in the structural connectome of the human brain. Proc Natl Acad Sci U S A (2014) 111:823-8. doi:10. 1073/pnas.1316909110

28. Coffey CE, Lucke JF, Saxton JA, Ratcliff G, Unitas LJ, Billig B, et al. Sex differences in brain aging: a quantitative magnetic resonance imaging study. Arch Neurol (1998) 55:169-79. doi:10.1001/ archneur.55.2.169

29. Courchesne E, Chisum HJ, Townsend J, Cowles A, Covington J, Egaas B, et al. Normal brain development and aging: quantitative analysis at in vivo MR imaging in healthy volunteers. Radiology (2000) 216:672-82. doi:10.1148/radiology. 216.3.r00au37672

30. Page DC. Sex and disease: do males and females read their genomes differently? Interdisciplinary Women's Health Research Symposium. Bethesda, MD: National Institutes of Health (2014).

31. Brady KT, Back SE, Greenfield SF, editors. Women and Addiction: A Comprehensive Handbook. New York, NY: Guilford Press (2011).

32. Becker JB, Hu M. Sex differences in drug abuse. Front Neuroendocrinol (2008) 29:36-47. doi:10. 1016/j.yfrne.2007.07.003 
33. Fattore L, Melis M, Fadda P, Fratta W. Sex differences in addictive disorders. Front Neuroendocrinol (2014) 35:272-84. doi:10.1016/j.yfrne.2014.04.003

34. Lynch WJ, Roth ME, Carroll ME. Biological basis of sex differences in drug abuse: preclinical and clinical studies. Psychopharmacology (Berl) (2002) 164:121-37. doi:10.1007/s00213-002-1183-2

35. Witt ED. Puberty, hormones, and sex differences in alcohol abuse and dependence. Neurotoxicol Teratol (2007) 29:81-95. doi:10.1016/j.ntt.2006.10.013

36. Dahan A, Kest B, Waxman AR, Sarton E. Sexspecific responses to opiates: animal and human studies. Anesth Analg (2008) 107:83-95. doi:10. 1213/ane.0b013e31816a66a4

37. Fattore L, Fadda P, Fratta W. Sex differences in the self-administration of cannabinoids and other drugs of abuse. Psychoneuroendocrinology (2009) 34(Suppl 1):S227-36. doi:10.1016/j. psyneuen.2009.08.008

38. Pogun S, Yararbas G. Sex differences in nicotine action. Handb Exp Pharmacol (2009) 192:261-91. doi:10.1007/978-3-540-69248-5_10

39. Finn DA, Beckley EH, Kaufman KR, Ford MM. Manipulation of GABAergic steroids: sex differences in the effects on alcohol drinking- and withdrawal-related behaviors. Horm Behav (2010) 57:12-22. doi:10.1016/j.yhbeh.2009.07.002

40. Vansickel AR, Stoops WW, Rush CR. Human sex differences in d-amphetamine self-administration. Addiction (2010) 105:727-31. doi:10.1111/j.13600443.2009.02858.x

41. Devito EE, Babuscio TA, Nich C, Ball SA, Carroll KM. Gender differences in clinical outcomes for cocaine dependence: randomized clinical trials of behavioral therapy and disulfiram. Drug Alcohol Depend (2014) 145:156-67. doi:10.1016/ j.drugalcdep.2014.10.007

42. Anker JJ, Zlebnik NE, Navin SF, Carroll ME. Responding during signaled availability and nonavailability of iv cocaine and food in rats: age and sex differences. Psychopharmacology (Berl) (2011) 215:785-99. doi:10.1007/s00213-011-2181-z

43. Carroll ME, Anker JJ. Sex differences and ovarian hormones in animal models of drug dependence. Horm Behav (2010) 58:44-56. doi:10.1016/ j.yhbeh.2009.10.001
44. McKee SA, Sinha R, Weinberger AH, Sofuoglu M, Harrison EL, Lavery M, et al. Stress decreases the ability to resist smoking and potentiates smoking intensity and reward. J Psychopharmacol (2011) 25:490-502. doi:10.1177/0269881110376694

45. Sinha R, Fox HC, Hong KI, Hansen J, Tuit K, Kreek MJ. Effects of adrenal sensitivity, stressand cue-induced craving, and anxiety on subsequent alcohol relapse and treatment outcomes. Arch Gen Psychiatry (2011) 68:942-52. doi:10. 1001/archgenpsychiatry.2011.49

46. Becker JB. Gender differences in dopaminergic function in striatum and nucleus accumbens. Pharmacol Biochem Behav (1999) 64:803-12. doi: 10.1016/S0091-3057(99)00168-9

47. Jacobs E, D'esposito M. Estrogen shapes dopamine-dependent cognitive processes: implications for women's health. J Neurosci (2011) 31:5286-93. doi:10.1523/JNEUROSCI.6394-10. 2011

48. Potenza MN, Hong KI, Lacadie CM, Fulbright RK, Tuit KL, Sinha R. Neural correlates of stressinduced and cue-induced drug craving: influences of sex and cocaine dependence. Am J Psychiatry (2012) 169:406-14. doi:10.1176/appi.ajp.2011. 11020289

49. Potenza MN, Steinberg MA, McLaughlin SD, Wu R, Rounsaville BJ, O'malley SS. Gender-related differences in the characteristics of problem gamblers using a gambling helpline. Am J Psychiatry (2001) 158:1500-5. doi:10.1176/appi.ajp.158.9.1500

50. Tavares H, Zilberman ML, Beites FJ, Gentil V. Gender differences in gambling progression. J Gambl Stud (2001) 17:151-9. doi:10.1023/A: 1016620513381

51. Potenza MN, Maciejewski PK, Mazure CM. A gender-based examination of past-year recreational gamblers. J Gambl Stud (2006) 22:41-64. doi:10.1007/s10899-005-9002-4

52. Hamilton KR, Mitchell MR, Wing VC, Balodis IM, Bickel W, Fillmore M, et al. Choice impulsivity: definitions, measurement issues, and clinical implications. Personal Disord (2014) (in press).

53. Hamilton KR, Littlefield AK, Anastasio NC, Cunningham KA, Fink L, Wing VC, et al. Rapidresponse impulsivity: definitions, measurement issues, and clinical implications. Personal Disord (in press).

54. Anker JJ, Gliddon LA, Carroll ME. Impulsivity on a Go/No-go task for intravenous cocaine or food in male and female rats selectively bred for high and low saccharin intake. Behav Pharmacol (2008) 19:615-29. doi:10.1097/FBP. 0b013e32830dc0ae

55. Jentsch JD, Taylor JR. Sex-related differences in spatial divided attention and motor impulsivity in rats. Behav Neurosci (2003) 117:76-83. doi:10. 1037/0735-7044.117.1.76

56. Lynch WJ, Roth ME, Mickelberg JL, Carroll ME. Role of estrogen in the acquisition of intravenously self-administered cocaine in female rats. Pharmacol Biochem Behav (2001) 68:641-6. doi:10.1016/ S0091-3057(01)00455-5

57. Quinn JJ, Hitchcott PK, Umeda EA, Arnold AP, Taylor JR. Sex chromosome complement regulates habit formation. Nat Neurosci (2007) 10:1398-400. doi:10.1038/nn1994

Conflict of Interest Statement: The authors declare that the research was conducted in the absence of any commercial or financial relationships that could be construed as a potential conflict of interest.

Received: 05 December 2014; accepted: 04 February 2015; published online: 18 February 2015.

Citation: Mitchell MR and Potenza MN (2015) Importance of sex differences in impulse control and addictions. Front. Psychiatry 6:24. doi: 10.3389/fpsyt.2015.00024 This article was submitted to Addictive Disorders and Behavioral Dyscontrol, a section of the journal Frontiers in Psychiatry.

Copyright (c) 2015 Mitchell and Potenza. This is an openaccess article distributed under the terms of the Creative Commons Attribution License (CC BY). The use, distribution or reproduction in other forums is permitted, provided the original author(s) or licensor are credited and that the original publication in this journal is cited, in accordance with accepted academic practice. No use, distribution or reproduction is permitted which does not comply with these terms. 